Journal of

Molecular Microbiology

and Biotechnology

\title{
Molecular Genetic and Crystal Structural Analysis of 1-(4-Hydroxyphenyl)-Ethanol Dehydrogenase from 'Aromatoleum aromaticum' EbN1
}

\author{
Imke Büsing $^{a} \quad H$. Wolfgang Höffken ${ }^{b} \quad$ Michael Breuer ${ }^{c} \quad$ Lars Wöhlbrand $^{a}$ \\ Bernhard Hauer ${ }^{c}$ Ralf Rabus ${ }^{a}$ d \\ anstitute for Chemistry and Biology of the Marine Environment (ICBM), Carl von Ossietzky University Oldenburg, \\ Oldenburg, ${ }^{b}$ Computational Chemistry and Biology, and ${ }^{c}$ White Biotechnology Research, BASF SE, Ludwigshafen, \\ and ${ }^{\mathrm{d}}$ Max Planck Institute for Marine Microbiology, Bremen, Germany
}

\section{Key Words}

Anaerobic $p$-ethylphenol degradation .

1-(4-Hydroxyphenyl)-ethanol dehydrogenase · In-frame deletion mutation - Proteogenomics - Crystal structure . Enantioselectivity · Denitrifier . 'Aromatoleum aromaticum' EbN1

\section{Abstract \\ The dehydrogenation of 1-(4-hydroxyphenyl)-ethanol to 4-hydroxyacetophenone represents the second reaction step during anaerobic degradation of $p$-ethylphenol in the denitrifying bacterium 'Aromatoleum aromaticum' EbN1. Previous proteogenomic studies identified two different proteins (ChnA and EbA309) as possible candidates for cata- lyzing this reaction [Wöhlbrand et al: J Bacteriol 2008;190: 5699-5709]. Physiological-molecular characterization of newly generated unmarked in-frame deletion and comple- mentation mutants allowed defining ChnA (renamed here as $\mathrm{Hped}$ ) as the enzyme responsible for 1-(4-hydroxyphenyl)- ethanol oxidation. Hped [1-(4-hydroxyphenyl)-ethanol de- hydrogenase] belongs to the 'classical' family within the short-chain alcohol dehydrogenase/reductase (SDR) super- family. Hped was overproduced in Escherichia coli, purified and crystallized. The X-ray structures of the apo- and NAD ${ }^{+}$}

soaked form were resolved at 1.5 and $1.1 \AA$, respectively, and revealed Hped as a typical homotetrameric SDR. Modeling of the substrate 4-hydroxyacetophenone (reductive direction of Hped) into the active site revealed the structural determinants of the strict (R)-specificity of Hped $\left(\mathrm{Phe}^{187}\right)$, contrasting the (S)-specificity of previously reported 1-phenylethanol dehydrogenase (Ped; $\mathrm{Tyr}^{93}$ ) from strain EbN1 [Höffken et al: Biochemistry 2006;45:82-93].

(C) 2015 S. Karger AG, Basel

\section{Introduction}

Aromatic compounds are structurally diverse and energy-rich compounds that challenge biodegradation with their chemical stability. Under oxic conditions (presence of $\mathrm{O}_{2}$ ), microorganisms employ highly reactive oxygen species $\left(\mathrm{O}_{2}\right.$-derived $)$ in oxygenase catalyzed reactions for compound activation and ring cleavage [e.g. Perez-Pantoja et al., 2012]. Under anoxic conditions (absence of $\mathrm{O}_{2}$ ), which dominate in many habitats such as marine and freshwater sediments as well as deeper soil layers, a large

Dedicated to Fritz Widdel on occasion of his 65th birthday. I.B. and H.W.H. contributed equally to this work.

\section{KARGER 125}

(c) 2015 S. Karger AG, Base

$1464-1801 / 15 / 0255-0327 \$ 39.50 / 0$

E-Mail karger@karger.com

www.karger.com $/ \mathrm{mmb}$
Ralf Rabus

Institute for Chemistry and Biology of the Marine Environment (ICBM)

Carl von Ossietzky University Oldenburg

DE-26111 Oldenburg (Germany)

E-Mail rabus@icbm.de 
diversity of (facultative) anaerobic bacteria occurs [Kaser and Coates, 2010; Widdel and Rabus, 2001; Widdel et al., 2010]. They have evolved a broad spectrum of intriguing reactions for substrate activation and dearomatization [Carmona et al., 2009; Fuchs et al., 2011; Gibson and Harwood, 2002; Widdel and Musat, 2010]. The present study organism, 'Aromatoleum aromaticum' EbN1 [Rabus and Widdel, 1995], is affiliated with the betaproteobacterial 'Aromatoleum'/Azoarcus/Thauera cluster, harboring a large fraction of the currently known anaerobic degraders of aromatic compounds [Widdel et al., 2010]. On the basis of its genome [Rabus et al., 2005], comprehensive physiological-proteomic experiments allowed the discovery of several new catabolic capacities and establishing 'A. aromaticum' EbN1 as a model organism to study anaerobic aromatic compound degradation on the systems biology level [Rabus et al., 2014; Wöhlbrand et al., 2007].

$p$-Ethylphenol enters the environment from anthropogenic as well as natural sources (see references cited in Wöhlbrand et al. [2008]). The anaerobic degradation of this phenolic compound was for the first time elucidated in 'A. aromaticum' EbN1, using differential proteogenomic and metabolite analysis [Wöhlbrand et al., 2008]. Notably, the initial activation and transformation of the ethyl side chain resembles that of ethylbenzene [Jobst et al., 2010; Kniemeyer and Heider, 2001a; Rabus et al., 2002], even though a completely different set of enzymes is involved: $p$-ethylphenol is initially hydroxylated to 1-(4-hydroxyphenyl)-ethanol, which is subsequently dehydrogenated to 4 -hydroxyacetophenone. The latter is presumably transformed to the central intermediate benzoyl-CoA via carboxylation, thiolytic removal of acetylCoA and reductive dehydroxylation (fig. 1a). All involved genes colocalize on the chromosome in an operon-like structure and most encoded proteins were specifically formed and identified in $p$-ethylphenol-adapted cells of 'A. aromaticum' EbN1 [Wöhlbrand et al., 2008].

With respect to the second reaction step in the anaerobic $p$-ethylphenol degradation pathway, the current proteogenomic evidence is ambiguous. Two dehydrogenases (EbA309, predicted alcohol dehydrogenase; ChnA, predicted cyclohexanol dehydrogenase) could catalyze an $\mathrm{NAD}^{+}$-dependent dehydrogenation of 1-(4-hydroxyphenyl)-ethanol to 4-hydroxyacetophenone. Moreover, the stereochemistry of the dehydrogenation reaction at the chiral carbon atom of 1-(4-hydroxyphenyl)-ethanol is unclear at present. Notably, the analogous reaction in the anaerobic ethylbenzene degradation pathway, catalyzed by $\mathrm{NAD}^{+}$-dependent 1-phenylethanol dehydrogenase (Ped), is (S)-specific [Höffken et al., 2006; Kniemeyer and Heider, 2001b]. Other known 1-phenylethanol-convert-
Fig. 1. Strategy and molecular results of knockout mutagenesis. a Pathway for anaerobic degradation of $p$-ethylphenol in 'A. aromaticum' EbN1 via 1-(4-hydroxyphenyl)-ethanol, 4-hydroxyacetophenone and 4-hydroxybenzoyl-CoA to the central intermediate benzoyl-CoA. The oxidation of 1-(4-hydroxyphenyl)-ethanol to 4-hydroxyacetophenone could in principle be catalyzed by either of the two predicted dehydrogenases Hped (renamed from ChnA) or EbA309. Products of genes marked in black were identified in a previous [Wöhlbrand et al., 2008] and this study. Names of the indicated gene products are as follows: AcsA, predicted acetoacetylCoA synthetase; Hped, 1-(4-hydroxyphenyl)-ethanol dehydrogenase; EbA309, putative alcohol dehydrogenase; PchCF, predicted p-ethylphenol methylenehydroxylase; TioL, predicted thiolase; XccABC, predicted 4-hydroxyacetophenone carboxylase. A scale model for the operon-like organization of the involved genes is displayed below the pathway. b Enlargement of the chromosomal organization of hped and ebA309 and their $3^{\prime}$ - and $5^{\prime}$-neighboring regions in the wild-type strain and of the deletion locus in the $\Delta$ hped/ebA309 mutant. The knockout mutant genotype consists only of the ebA309 start and hped stop codon, separated by a PstI restriction site. The location of applied primer pairs on the chromosomal DNA of strain EbN1 for the construction of the knockout vector pK19 SebA310_ebA303/tioL (grey), for the identification of the $\Delta$ hped/ebA309 mutant (tioL/ebA310) and for the amplification of specific gene products is indicated. Selected PCR product lengths are given below and nucleotide sequences are listed in table 2 . c Electropherogram of PCR products obtained from wild-type 'A. aromaticum' EbN1 (wt) and the $\Delta$ hped/ebA309 mutant $(\Delta)$ DNA applying the primer pair tioL/ebA310 binding to the adjacent genes of hped and ebA309. PCR resulted in a shorter mutant specific amplicon ( $350 \mathrm{bp}$ ) compared to the wild-type specific product (2000 bp). No amplification of hped and $e b A 309$ from the DNA of strain $\Delta h p e d / e b A 309$ using gene specific primer pairs was observed. $\mathbf{d}$ Expression analysis of genes adjacent to the knockout locus revealed unimpaired expression of $t i o L$ and $e b A 310$ in the deletion mutant. Expression of hped and $e b A 309$ was further verified in the respective complemented strains, i.e. the hped-complemented mutant, ebA309-complemented mutant and the hped/ebA309-complemented mutant. Total RNA for cDNA synthesis of all strains was prepared from cells anaerobically grown with 4-hydroxyacetophenone. Controls without reverse transcriptase revealed no PCR products (not shown). e Proteins of the anaerobic $p$-ethylphenol degradation pathway identified by shotgun proteomics in the wildtype, the $\Delta$ hped/ebA309 mutant and the complementation strains grown with 4-hydroxyacetophenone. Mascot scores for all identified proteins are given. In accordance to the gene expression analysis, the proteins TioL and EbA310, encoded adjacent to the knockout locus, were present in the knockout mutant, while Hped and EbA309 could not be detected. However, both proteins were identified in the respective complemented strains.

(For figure see next page.) 

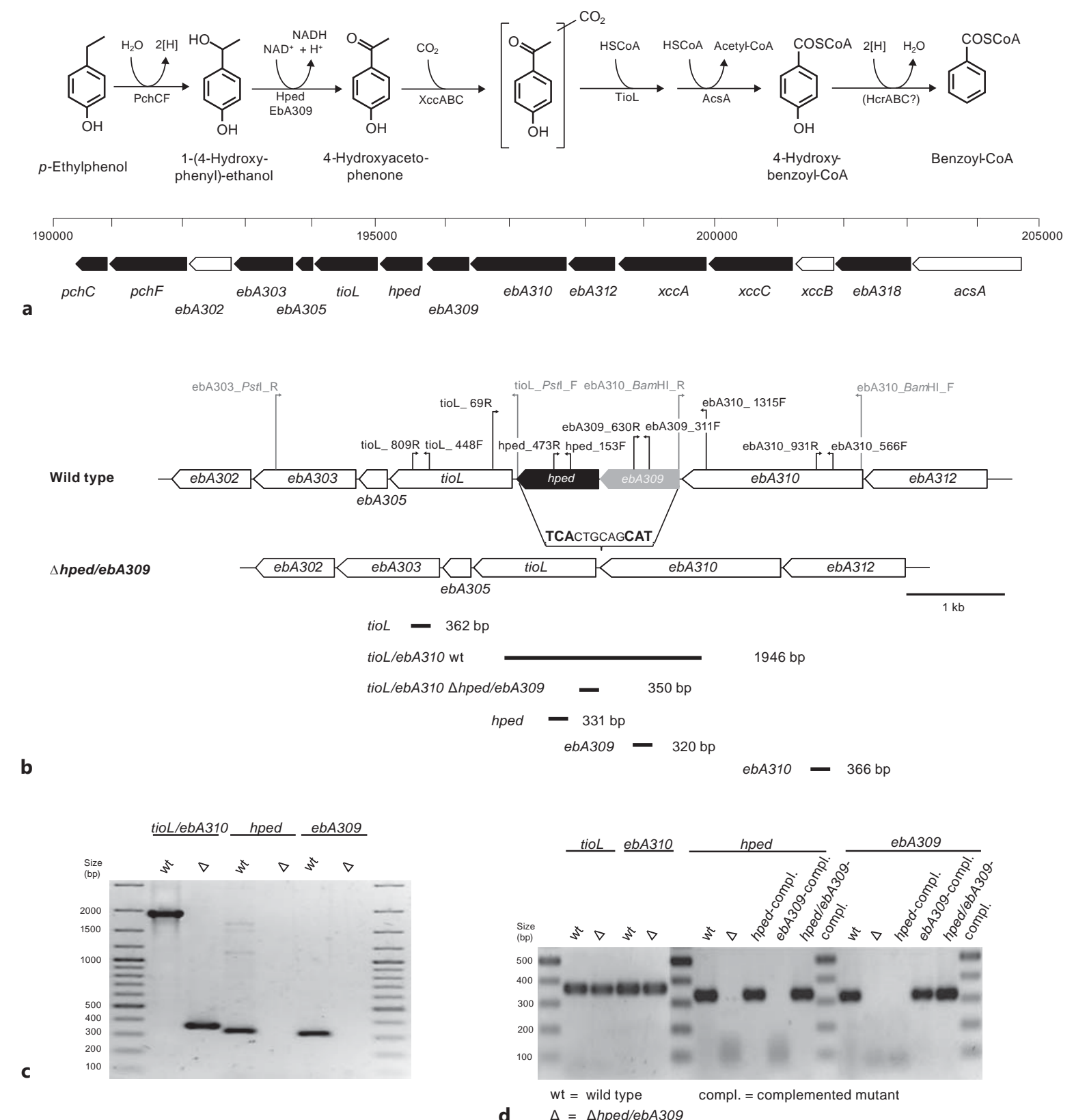

\begin{tabular}{|c|c|c|c|c|c|c|c|}
\hline \multirow[b]{2}{*}{ Accession } & \multirow[b]{2}{*}{ Protein } & \multirow[b]{2}{*}{ Predicted function } & \multicolumn{5}{|c|}{ Mascot Score } \\
\hline & & & wt & $\Delta$ & $\begin{array}{c}\text { hped/ebA309- } \\
\text { compl. }\end{array}$ & $\begin{array}{l}\text { hped- } \\
\text { compl. }\end{array}$ & $\begin{array}{l}\text { ebA309- } \\
\text { compl. }\end{array}$ \\
\hline ebA299 & PchC & Probable $p$-ethylphenol methylenehydroxylase subunit & 119.3 & 155.5 & 210.7 & 163.7 & 173.7 \\
\hline ebA300 & PchF & Probable $p$-ethylphenol methylenehydroxylase subunit & 754.6 & 814.7 & 570.0 & 756.7 & 392.8 \\
\hline ebА303 & ЕbА303 & Alcohol dehydrogenase & 291.7 & 335.8 & 209.4 & 184.9 & 99.4 \\
\hline ebA305 & EbA305 & Conserved hypothetical protein & 239.9 & 118.4 & 107.2 & 126.8 & 100.4 \\
\hline ebA306 & Tiol & Predicted thiolase & 516.2 & 555.2 & 293.9 & 255.9 & 118.5 \\
\hline ebA307 & Hped & Hydroxy-phenylethanol dehydrogenase & 460.2 & 0.0 & 67.6 & 112.2 & 0.0 \\
\hline ebA309 & EbA309 & Putative dehydrogenase & 418.2 & 0.0 & 73.2 & 0.0 & 45.9 \\
\hline ebA310 & EbA310 & FAD linked oxidase & 504.0 & 722.3 & 415.9 & 417.5 & 333.5 \\
\hline ebA312 & EbA312 & Predicted sugar phosphatases of the HAD superfamily & 234.6 & 297.0 & 144.6 & 57.6 & 150.1 \\
\hline ebA314 & $\mathrm{XccA}$ & Putative carboxylase subunit of acetyl-CoA carboxylase-like enzyme & 407.4 & 571.8 & 167.0 & 172.8 & 243.5 \\
\hline ebA316 & $\mathrm{XccC}$ & Biotin carboxylase subunit of acetyl-CoA carboxylase-like enzyme & 637.2 & 275.2 & 191.0 & 252.8 & 190.0 \\
\hline ebA318 & EbA318 & Conserved hypothetical protein & 449.9 & 539.4 & 381.6 & 185.8 & 199.2 \\
\hline
\end{tabular}

1-(4-Hydroxyphenyl)-Ethanol DH of Strain EbN1
J Mol Microbiol Biotechnol 2015;25:327-339

DOI: $10.1159 / 000439113$ 
ing dehydrogenases are either $(S)$-specific and $\mathrm{Zn}^{2+}$-dependent (Rhodococcus erythropolis [Abokitse and Hummel, 2003]) or (R)-specific and $\mathrm{NADP}^{+}$-dependent ( $\mathrm{Lac}^{-}$ tobacillus brevis [Niefind et al., 2003]). In general, such enantioselective $\mathrm{NAD}(\mathrm{P})^{+}$-dependent dehydrogenases operating in reductive direction are valuable catalysts for the biotechnological synthesis of chiral compounds [Hummel, 1999].

In the present study, application of molecular genetics (unmarked in-frame deletion and in trans expression) allowed identifying ChnA (renamed here as Hped) as the enzyme responsible for 1-(4-hydroxyphenyl)-ethanol oxidation in 'A. aromaticum' EbN1. Moreover, analysis of the Hped crystal structure resolved the $(R)$-specificity of the dehydrogenation reaction.

\section{Results and Discussion}

To avoid ambiguous assignments of gene names, from here on hped for 1-(4-hydroxyphenyl)-ethanol dehydrogenase is used instead of the original designation $\operatorname{chn} A$, which had been solely based on product homology to described cyclohexanone dehydrogenase [Rabus et al., 2005].

\section{Generation and Molecular Characterization of an}

Unmarked hped/ebA309 In-Frame Deletion and Its

Complementation Mutants

The second reaction of the anaerobic p-ethylphenol degradation pathway in 'A. aromaticum' EbN1 may be performed by two predicted dehydrogenases, Hped and EbA309, adjacently encoded within the p-ethylphenol gene cluster (fig. 1a). Since both proteins are specifically formed during anaerobic growth of strain $\mathrm{EbN} 1$ with $p$ ethylphenol and 4-hydroxyacetophenone, respectively, it was unclear which enzyme catalyzes the oxidation of 1-(4-hydroxyphenyl)-ethanol to 4-hydroxyacetophenone [Wöhlbrand et al., 2008]. To determine the catalytically active enzyme, an unmarked in-frame deletion mutant ( $\Delta$ hped/ebA309) was generated by means of homologous recombination. Notably, duplicating the size of the homologous region in the knockout vector pronouncedly increased the knockout efficiency $(\sim 50 \%)$ as compared to previous experiments $(<4 \%$ [Wöhlbrand and Rabus, 2009]). The mutant genotype harbors only the start codon of hped and the stop codon of ebA309 separated by a PstI restriction site, maintaining the reading frame. Accordingly, neither hped nor ebA309 could be amplified by PCR from genomic DNA of the mutant strain using gene-specific primers. In addition, primers located in the $5^{\prime}$ - and $3^{\prime}$-neighboring genes ebA310 and tioL, respectively, yielded a small 350-bp mutant-specific product instead of a 2,000-bp wild-type amplicon (fig. 1 b, c). The presence of polar effects caused by the deletion can be excluded since transcripts of the neighboring genes $e b A 310$ and tioL were detected in the mutant growing with 4-hydroxyacetophenone (fig. 1d). Furthermore, 5 of the 6 proteins encoded downstream of $h p e d$, as well as 5 of the 7 proteins encoded upstream of $e b A 309$, were identified in these cells (fig. 1e).

In order to restore the wild-type phenotype and to identify the enzyme catalyzing the dehydrogenation of 1-(4-hydroxyphenyl)-ethanol, three complementation mutants were generated: a hped/ebA309-complemented mutant (genotype: $\Delta$ hped/ebA309, pBBRMCS-4 Shped/ ebA309), a hped-complemented mutant (genotype: $\Delta$ hped/ebA309, pBBRMCS-4 Shped) and a ebA309complemented mutant (genotype: $\Delta$ hped/ebA309, pBBRMCS-4 SebA309). The complemented genes were constitutively expressed from the broad host range plasmid pBBR1MCS- 4 as the presence of their transcripts and proteins in the respective strains could be confirmed by transcript and proteomic analysis (fig. 1d, e).

\section{Identification of Hped as Productive Dehydrogenase}

for 1-(4-Hydroxyphenyl)-Ethanol Oxidation

The generated deletion mutant $\Delta$ hped/ebA309 revealed no growth with $p$-ethylphenol after $80 \mathrm{~h}$ of incubation, while the wild-type strain reached the stationary growth phase already after $45 \mathrm{~h}$. Interestingly, the $\mathrm{hped} /$ ebA309-complemented and hped-complemented mutant strains restored growth with $p$-ethylphenol after a prolonged lag-phase, though with decreased maximum growth rate and yield (fig. 2a). The latter may be due to the $p$-ethylphenol-evoked solvent stress in combination with the applied ampicillin (for plasmid maintenance). Notably, in trans expression of ebA309 did not restore anaerobic growth with $p$-ethylphenol, suggesting Hped to be the only catalytically active dehydrogenase for the investigated reaction. In contrast to $p$-ethylphenol, growth with 4-hydroxyacetophenone was unaffected by the gene deletion, as Hped and EbA309 are not required for degradation of this intermediate of the anaerobic $p$-ethylphenol degradation pathway (fig. 2b). The hped-complemented mutant strain revealed a prolonged lag-phase, while maximal growth rate and optical density similar to the wild-type strain EbN1 were obtained. To exclude any secondary effects caused by the gene deletion, growth with all known substrates of strain EbN1 other than $p$ - 


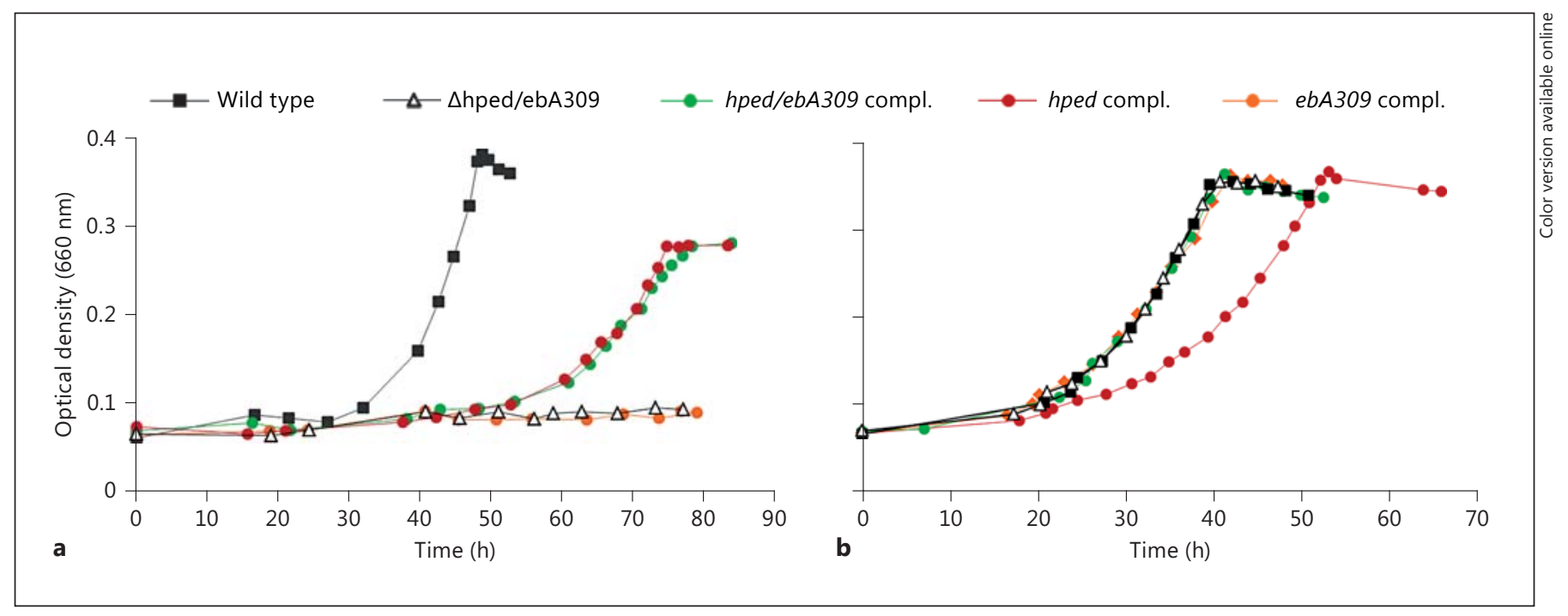

Fig. 2. Anaerobic growth experiments. 'A. aromaticum' EbN1 wild-type, $\Delta$ hped/ebA309 mutant and the complemented mutant strains were grown under nitrate-reducing conditions with $p$-ethylphenol (a) and 4-hydroxyacetophenone (b). Cultures were inoculated with cells adapted to anaerobic growth with 4-hydroxyacetophenone.

ethylphenol was tested with the $\Delta$ hped/ebA309 mutant, revealing no differences to the wild type. This molecular genetic evidence for the hped encoded dehydrogenase to be solely responsible for 1-(4-hydroxyphenyl)-ethanol oxidation to 4-hydroxyacetophenone in 'A. aromaticum' EbN1 motivated the continuative enzymatic analysis with overproduced Hped in Escherichia coli extracts (see Preliminary Enzymatic Characterization of Hped vs. Ped, as well as fig. S2 and S3 in the supplementary material; see www.karger.com/doi/10.1159/000439113 for all suppl. material) and structural studies with the purified and crystallized Hped protein.

\section{Enantioselectivity}

EbA309 has opposite enantioselectivity for acetophenone derivatives in comparison to Hped. Acetophenone, for example, is converted by Hped almost exclusively (ee: $>99.7 \%$ ) to the respective (1R)-1-phenylethanol, whereas EbA309 gives rise to (1S)-1-phenylethanol (ee: >99.7\%). In accordance with Prelog [1964], we can safely assign Hped as a Prelog-dehydrogenase contrary to EbA309, which is an anti-Prelog-dehydrogenase.

\section{The Overall Protein Structure}

The structure of Hped was solved as apo- and holoform with a resolution of 1.5 and $1.1 \AA$, respectively. The quality of the structures is reflected by the good R-factors and excellent stereochemical parameters (online suppl. table 1). Hped is a typical member of the short-chain alcohol dehydrogenase/reductase (SDR) superfamily with a classical Rossmann fold structure. The central twisted parallel $\beta$-sheet with seven strands is flanked by six $\alpha$ helices, three on each side. Two additional short helices ( $\alpha$ FG1 and $\alpha$ FG2) between strand $\beta$ F and helix $\alpha \mathrm{G}$ form the substrate-binding site (fig. $3 \mathrm{a}-\mathrm{c}$ ). There are two monomers of 248 amino acid residues each in the crystallographic asymmetric unit.

\section{Sequence and Structural Features Compared with} Other SDRs

Hped belongs to the large SDR superfamily, members of which have been intensively studied with respect to structure, catalytic mechanism and evolution (e.g. [Jörnvall et al., 1981, 2010; Ladenstein et al., 2008]). According to Kallberg et al. [2002], Hped belongs to the cD1d-subfamily of the 'classical' family within the SDR superfamily. Comparison to sequences of other SDRs shows, with the exception of one, that all highly conserved and structurally relevant amino acids as tabulated by Oppermann et al. [2003] and Kallberg et al. [2002] are also present in Hped (fig. 3d), and are discussed in the following paragraphs.

The first motif is the $\mathrm{TGX}_{3} \mathrm{GXG}$ sequence. The $\mathrm{O} \gamma$ $\mathrm{Thr}^{11}$ forms a hydrogen bond to the main chain nitrogen of $A s n^{89}$, stabilizing the ends of strands $\beta A$ and $\beta D$ of the central $\beta$-sheet. At position 12, a larger amino acid than 
glycine would lead to a clash with $\mathrm{Ala}^{90}$ and also interfere with the cofactor binding. Gly ${ }^{16}$ and $\mathrm{Gly}^{18}$ are located at the $\mathrm{N}$-terminal end of helix $\alpha \mathrm{B}$. A larger amino acid at position 16 would clash with the phosphates of the $\mathrm{NAD}^{+}$ cofactor. A larger amino acid at position 18 would clash with the carbonyl oxygen of Gly ${ }^{12}$ and ND2 Asn ${ }^{89}$.

The $\mathrm{Asp}^{36}$ defines Hped as a cD1d-subfamily member and is responsible for binding $\mathrm{NAD}^{+}$instead of $\mathrm{NADP}^{+}$ as the cofactor. The phosphoryl group of $\mathrm{NADP}^{+}$would be electrostatically repulsed by the carboxyl group of Asp $^{36}$.

Asp $^{60}$ in the bacterial $3 \beta / 17 \beta$-hydroxysteroid dehydrogenase is characterized by Oppermann et al. [2003] as stabilizing the adenine ring pocket with weak interaction to the adenine. The equivalent $\mathrm{Asp}^{62}$ in Hped has the same role. The oxygen OD1 Asp ${ }^{62}$ forms a hydrogen bond to $\mathrm{N} \mathrm{Ala}^{64}$ and stabilizes the loop connecting the $\beta$-strand $\mathrm{C}$ and helix $\alpha \mathrm{D}$. The OD1 $\mathrm{Asp}^{62}$ also forms a hydrogen bond to the adenosine nitrogen N6A with a distance of $2.96 \AA$.

The NNAG motif shows different conformations in the apo- and holo-form (see Further Details on the Structure of Hped in the supplementary material).

The four amino acids Asn ${ }^{114}$, Ser $^{142}$, Tyr $^{155}$ and Lys ${ }^{159}$ form the catalytic tetrad. For further details see Structural Insights into the Catalytic Mechanism of Hped below.

The side chain amino group of Asn ${ }^{181}$ (Asn ${ }^{179}$ according to Oppermann et al. [2003]) is involved in a tight network of hydrogen bonds. The oxygen OD1 Asn ${ }^{181}$ is hydrogen bonded to the main chain nitrogen of $\operatorname{Ser}^{237}$ (3.0 $\AA$ ) and also makes a weak $\mathrm{CH}-\mathrm{O}$ hydrogen bond to the $\mathrm{C} \alpha$-atom of $\mathrm{Thr}^{235}$ (3.18 $\AA$ ). The nitrogen ND2 Asn ${ }^{181}$ is hydrogen bonded to the main chain oxygen of $\mathrm{Val}^{234}$ $(2.98 \AA)$ and to a water molecule (No. 2169) with a distance of $2.88 \AA$. This water molecule is further hydrogen bonded to the carbonyl oxygen atoms of Leu ${ }^{226}(3.13 \AA)$ and $\operatorname{Ile}^{137}(2.88 \AA)$. This presumably reinforces the core of the monomer structure by connecting strands $\beta \mathrm{F}$ and $\beta \mathrm{E}$, helix $\alpha \mathrm{G}$, and the loop preceding helix $\alpha \mathrm{G}$, as also

Fig. 3. Overall structure of (1R)-1-(4-hydroxyphenyl)-ethanol dehydrogenase (Hped) from 'A. aromaticum' EbN1. a Structural overview of the Hped monomer with $\alpha$-helices highlighted in red and $\beta$-strands in blue. The shown $\mathrm{NAD}^{+}$-cofactor is modeled into the structure. The labeling of secondary structure elements is according to Ghosh et al. [1991]. b Schematic diagram of secondary structure elements and their consecutive arrangement. c Quarternary structure of the tetramer. Subunits $A, A^{\prime}, B$ and $B^{\prime}$ are indicated by letters and colored blue, yellow, brown and green (color found in other 'classical' SDRs. The central role of Asn ${ }^{181}$ for the structural integrity of Hped is further evidenced by the close spatial proximity to Phe $\mathrm{P}^{233}$ (see Further Structural Properties of Hped below).

The proline of the PG motif (Pro ${ }^{185}$ in Hped), which is very highly conserved within the 'classical' family among SDRs, is located at the back of the nicotinamide ring of $\mathrm{NAD}^{+}$and seems to stabilize the active site. In Hped, the glycine of the PG motif is replaced by Ala ${ }^{186}$, which reduces the flexibility of this part of the chain at the beginning of the substrate-binding loop. Ala ${ }^{186}$ is followed by Phe ${ }^{187}$, which confines the substrate-binding pocket to assure the $(R)$-stereospecificity of the (de)hydrogenation reaction. Like in many other SDRs, $\mathrm{Thr}^{190}$ forms a hydrogen bond to the carboxamide of the nicotinamide ring (OG1-N7N, $3.05 \AA$ ).

\section{Further Structural Properties of Hped}

The crystallographic two-fold axis generates the biologically active homotetramer with two types of hydrophobic dimerization interfaces and a 222 symmetry, as seen for many SDRs (fig. 3c). Phe ${ }^{233}$ plays a major role in the interaction between the monomers. It protrudes into the adjacent chain (monomer) and interacts with the two substrate-binding loops of the other chain (online suppl. fig. 4). Notably, $\mathrm{Phe}^{234}$ in Ped (analogous to $\mathrm{Phe}^{233}$ in Hped) is localized in the same spatial arrangement between two different chains. Phe ${ }^{234}$ was implicated in cooperativity of Ped [Höffken et al., 2006], which might also be the case with $\mathrm{Phe}^{233}$ and Hped. The hydrogen bonding of $\mathrm{NAD}^{+}$to the $\mathrm{N}$-terminus of helix $\alpha \mathrm{B}$ via $\mathrm{O} 1-\mathrm{N}$ Gly ${ }^{18}$ $(3.13 \AA)$ and $\mathrm{O} 2-\mathrm{N} \mathrm{Ile}^{17}(2.87 \AA)$ is displayed in online supplementary figure 5 . A comparison of the Hped structure and $\mathrm{NAD}^{+}$binding with those of Ped [Höffken et al., 2006], LVR [Sogabe et al., 2003] and FabG [Javidpour et al., 2014] is provided in online supplementary figures 6 and 7.

Additional information on the homodimer and tetramer, additional ligands, comparison of $\mathrm{A}$ and $\mathrm{B}$ chain, the in online version only). The arrows represent the symmetry axes, the R-axis is perpendicular to the paper. d Primary sequence of Hped highlighting localization of secondary structure elements, amino acids and motifs conserved among SDRs (bold, conserved amino acids; underlined, functionally defined amino acids according to Oppermann et al. [2003]; grey shading, motifs as defined by Kallberg et al. [2002] and catalytically relevant amino acids; green, $\mathrm{NAD}(\mathrm{H})$ binding; red, catalytic tetrad; white on blue background, steric forcing).

(For figure see next page.) 


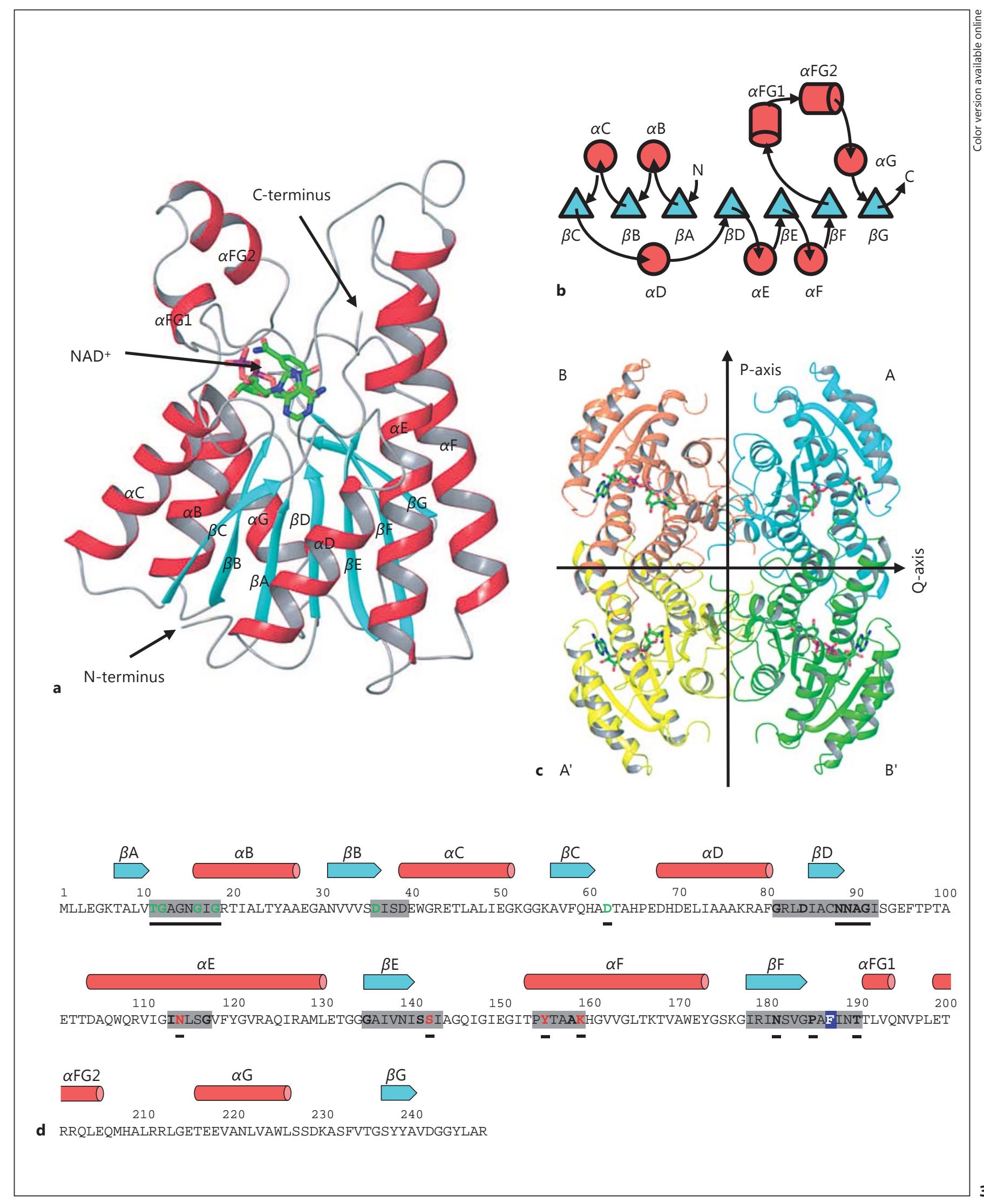

1-(4-Hydroxyphenyl)-Ethanol DH of Strain EbN1
J Mol Microbiol Biotechnol 2015;25:327-339 DOI: $10.1159 / 000439113$
333 


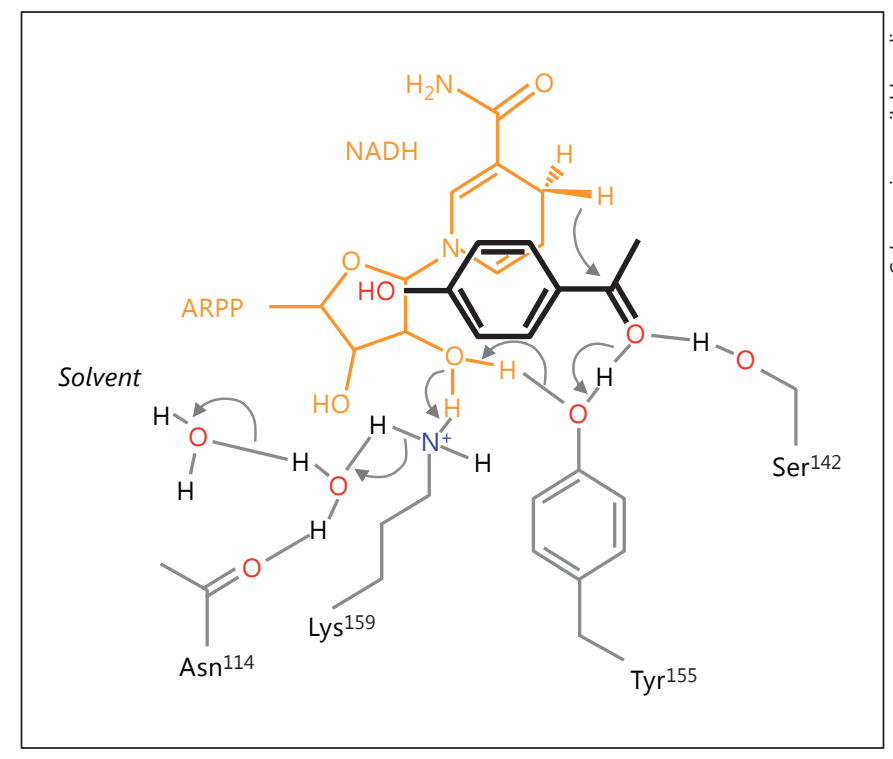

Fig. 4. Scheme of the reaction mechanism of Hped. The substrate 4 -hydroxyacetophenone is marked in black/bold, the NAD ${ }^{+}$cofactor in orange and the active site amino acids participating in catalysis in grey.

apo- and holo-structures as well as the comparison of apo- and holo-structures of Hped is provided in the section Further Details on the Structure of Hped in the online supplementary material and online supplementary table 2.

\section{Structural Insights into the Catalytic Mechanism of Hped}

The catalytic site of Hped reflects the well-known arrangement of the catalytic residues seen in almost all SDRs (fig. 4). Tyr ${ }^{155}$ functions as the catalytic base, while Ser ${ }^{142}$ helps to orient the substrate in an optimal position for hydride transfer. An acetate ion (see Further Details on the Structure of Hped - The Holo-Structure in the online suppl. material) is located in a position where the substrate carbonyl group is supposed to be positioned for hydride transfer. One oxygen atom of the acetate is hydrogen bonded to OH Tyr ${ }^{155}(2.55 \AA)$ and to OG Ser ${ }^{142}$ (2.61 $\AA$ ). This supports the role of Ser ${ }^{142}$ in stabilizing the correct orientation. The methyl group of the acetate points into a hydrophobic small pocket, which is responsible for the Prelog specificity of Hped. Lys ${ }^{159}$ interacts with the nicotinamide ribose and lowers the $\mathrm{pK}_{\mathrm{a}}$ of the $\mathrm{OH} \mathrm{Tyr}{ }^{155}$ [Oppermann et al., 2003]. Asn ${ }^{114}$ is supposed to be part of the proton relay system. The main chain carbonyl oxygen forms a hydrogen bond to a highly con- served water molecule, which in turn is hydrogen bonded to the catalytic Lys ${ }^{159}$. The side chain conformation of Asn ${ }^{114}$ differs in the apo- and holo-form. Reduction of 4-hydroxyacetophenone should involve a nucleophilic attack of the pro-S hydride donated by NADH. Hydride transfer from nicotinamide occurs stereoselectively at the re side rather than the si side of 4-hydroxyacetophenone. While Hped $(R)$-specifically hydrogenates 4 -hydroxyacetophenone and acetophenone, Ped does so $(S)$-specifically with acetophenone.

\section{Docking of 4-Hydroxyacetophenone into the Active} Sites of Hped and Ped

The substrates 4-hydroxyacetophenone and acetophenone have been docked with the program GLIDE into the active sites of holo-Hped and holo-Ped in order to get an unbiased view of the stereo preference of these two enzymes (fig. 5). The positioning of the keto group was used as a criterion for a catalytically productive pose. In Hped, acetophenone was placed with the highest docking score with the keto carbon with a distance of $3.63 \AA$ to $\mathrm{C} 4$ of the nicotinamide and the oxygen forming a hydrogen bond with a distance of $2.87 \AA$ to the hydroxyl group of Tyr ${ }^{155}$ (fig. 5a). In Ped, both molecules were placed with the highest docking score in identical positions with the keto carbon atom in a distance of $3.83 \AA$ to the $\mathrm{C} 4$ of the nicotinamide ring and the oxygen atom in hydrogen bond distance (3.37 $\AA$ ) to the hydroxyl group of the active site $\operatorname{Tyr}^{155}$ (fig. 5b). For 4-hydroxyacetophenone, the third highest ranked pose gave the same catalytically productive placement. The two higher ranked poses form a hydrogen bond to the oxygen of the phosphate (NO1) leading to a larger distance to $\mathrm{C} 4(>4.0 \AA)$. The binding poses will lead to the $(S)$-alcohol for Ped and $(R)$-alcohol for Hped, reflecting the steric requirements of the binding pocket due to $\mathrm{Tyr}^{93}$ in Ped and Phe ${ }^{187}$ in Hped.

\section{Pathway Inherent Enantioselectivity of Hped and Ped}

The opposite enantioselectivities of Hped ( $R$-specific) and Ped ( $S$-specific) from 'A. aromaticum' EbN1 agree with the assumed stereospecificities of the preceding enzymes catalyzing the respective initial steps in the two different degradation pathways. While the proposed 4-ethylphenol methylenehydroxylase (PchCF) has not been purified yet from 'A. aromaticum' EbN1, the analogous enzyme from Pseudomonas putida JD1 was previously demonstrated to form the (R)-isomer of 1-(4-hydroxyphenyl)-ethanol from $p$-ethylphenol [Reeve et al., 1990]. In contrast, activity and structural analysis of ethylbenzene dehydrogenase from 'A. aromaticum' EbN1 
Fig. 5. Stereo image of $\mathrm{NADH}$ and aromatic substrates modeled in active sites of $R$ and $S$-selective dehydrogenases from ' $A$. aromaticum' EbN1. a Hped; for visual clarity, Leu ${ }^{192}$ (grey, thin-lined) was not included in the calculation of the protein surface. b Ped, the aromatic substrates 4-hydroxyacetophenone (purple), and acetophenone (salmon) are displayed as overlay (color in online version only). Amino acid side chains which restrict the substrate binding pocket and constitute stereospecificity are Phe $\mathrm{P}^{187}$ in Hped and $\mathrm{Tyr}^{93}$ in Ped (space filling representation, red).
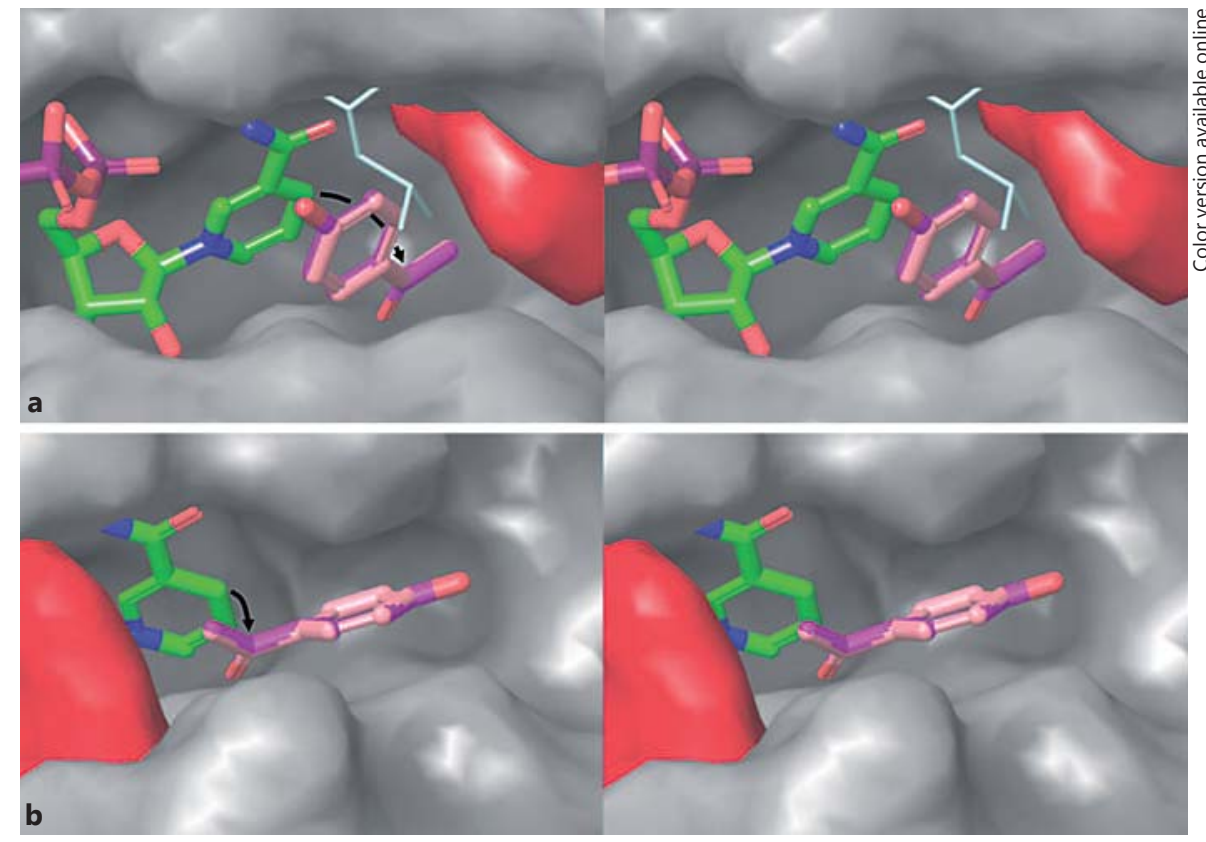

demonstrated formation of the (S)-isomer of 1-phenylethanol [Kloer et al., 2006; Kniemeyer and Heider, 2001a]. The (S)-enantioselectivity of EbA309 determined by enzymatic measurements explains why this dehydrogenase cannot substitute Hped in oxidation of (1R)-(4hydroxyphenyl)-ethanol, despite the chromosomal colocalization and coexpression of the coding genes ( $h p e d$ and ebA309).

\section{Applied Relevance}

The genome of 'A. aromaticum' EbN1 contains multiple dehydrogenase-encoding genes [Rabus et al., 2005], the substrate specificity and potential enantioselectivity of which is in most cases unknown. Here, molecular genetics allowed demonstrating that Hped and not EbA309 is responsible for oxidizing 1-(4-hydroxyphenyl)-ethanol to 4-hydroxyacetophenone as the second reaction step in the anaerobic degradation of $p$-ethylphenol. This adds to our current knowledge of dehydrogenases involved in the microbial degradation of aromatic compounds [MacKintosh and Fewson, 1987]. Furthermore, results from the crystal structure analyses corroborated the potential of these dehydrogenases for producing enantiopure secondary alcohols from a wide range of prochiral ketones and esters as recently demonstrated for Ped from 'A. aromaticum' EbN1 [Breuer et al., 2008; Dudzik et al., 2015; Gröger et al., 2006; Hummel et al., 1999]. Conversely, only one enantiomer can be selective- ly oxidized from a racemic mixture of an alcohol. Our preliminary characterization of EbA309 and Hped reveals that both biocatalysts show significant potential in this respect, as both convert acetophenone and derivatives thereof with high enantioselectivity [Breuer et al., 2008].

\section{Materials and Methods}

\section{Bacterial Strains and Cultivation}

The cultivation of 'A. aromaticum' EbN1 and E. coli in liquid and on solid medium was performed as described previously [Rabus and Widdel, 1995; Wöhlbrand and Rabus, 2009]. Strains used and generated in this study are given in table 1.

\section{Molecular Genetics (Unmarked In-Frame Deletion)}

The isolation of genomic DNA and plasmids was performed according to standard methods [Sambrook and Russel, 2001]. Oligonucleotide primers were designed using the software Lasergene (version 7.0; DNASTAR, Madison, Wis. USA) and purchased from Biomers.net GmbH (Ulm, Germany). Details on primers used in this study are summarized in table 2.

For reasons of unambiguous nomenclature, the new gene designation $h p e d$ is used throughout this report instead of the original gene name $\operatorname{ch} n A$. The vector for unmarked knockout of hped and ebA309 (pK19 SebA310_ebA303/tioL) was based on the suicide plasmid pK19mobsacB [Schäfer et al., 1994] containing $2.6 \mathrm{kbp}$ of the $5^{\prime}$ - and $1.6 \mathrm{kbp}$ of the $3^{\prime}$-flanking regions of hped and $e b A 309$, respectively, to allow for high double-crossover efficiency. The start codon of ebA309 and the stop codon of hped separated by a Pst I restriction site were preserved in the knockout construct to 
Table 1. Strains and plasmids used in this study

\begin{tabular}{|c|c|c|}
\hline & Genotype and/or characteristics & Reference \\
\hline \multicolumn{3}{|l|}{ Strains } \\
\hline 'A. aromaticum' EbN1 & Wild type & Widdel and Rabus, 2001 \\
\hline EbN1 hped/ebA309-complemented mutant & $\Delta$ hped, $\Delta e b A 309, \mathrm{pBBR} 1 \mathrm{MCS}-4 \Omega e b A 309 / \mathrm{hped}$ & This study \\
\hline EbN1 hped-complemented mutant & shped, $\Delta e b A 309$, pBBR1MCS-4 Shped & This study \\
\hline EbN1 ebA309-complemented mutant & $\Delta h p e d, \Delta e b A 309, \mathrm{pBBR} 1 \mathrm{MCS}-4 \Omega e b A 309$ & This study \\
\hline \multicolumn{3}{|l|}{ Plasmids } \\
\hline pK19mobsacB & $\mathrm{Km}^{\mathrm{R}}$, sacB modified from B. subtilis, lacZ $\alpha$ & Schäfer et al., 1994 \\
\hline pK19 $\Omega e b A 310$ & $\mathrm{Km}^{\mathrm{R}}$, sacB modified from $B$. subtilis, lacZ $\alpha, e b A 310$ from strain EbN1 & This study \\
\hline pK19 @ebA310_ebA303/tioL & $\begin{array}{l}\mathrm{Km}^{\mathrm{R}}, s a c B \text { modified from } B . \text { subtilis, lacZ } \alpha, e b A 310, e b A 303 \text { and } \\
\text { part of tioL from strain EbN1 }\end{array}$ & This study \\
\hline pBBR1MCS-4 & $\mathrm{Ap}^{\mathrm{R}}, m o b, l a c Z \alpha$ & Kovach et al., 1995 \\
\hline pJOE $\Omega$ hped & ColE1, bla, $\mathrm{Ap}^{\mathrm{R}}, \mathrm{P}_{\text {rhaBAD }}, r r n B, h p e d$, expression vector & This study \\
\hline
\end{tabular}

generate an in-frame deletion mutant and avoid polar effects. The $5^{\prime}$ - and $3^{\prime}$-regions were amplified by PCR from the genomic DNA of strain EbN1 using a high-fidelity polymerase (Phusion ${ }^{\circledR}$; Thermo Fisher Scientific, Dreieich, Germany; table 2). Initially, the $3^{\prime}$-homologous region (containing ebA310) was cloned into the vector using $B a m \mathrm{HI}$ and Pst I restriction sites as previously described [Wöhlbrand and Rabus, 2009], whereby plasmid pK19 $\Omega e b A 310$ was generated. Subsequently, the $5^{\prime}$-region (harboring tioL, ebA305 and partial ebA303) was cloned into pK19 $\Omega e b A 310$ using the PstI restriction site, yielding the knockout vector pK19 SebA310_ebA303/tioL. Nucleotide sequences were verified by sequencing using the ABI PRISM ${ }^{\circledR}$ BigDye ${ }^{\mathrm{TM}}$ Terminator v 3.0 Kit (Applied Biosystems, Foster City, Calif., USA) and the ABI 3100 sequencer system (Applied Biosystems). The validated

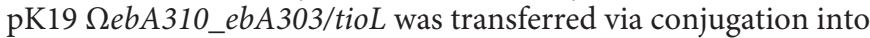
strain EbN1 as described [Wöhlbrand and Rabus, 2009]. Kanamycin-resistant colonies of strain EbN1 (i.e. single cross-over) were screened for vector integration by PCR using primers binding in $e b A 310$ and tioL, respectively, yielding a 2-kbp wild-type and a 350 -bp vector amplicon (fig. $1 \mathrm{~b}$, table 2 ). Induction of a second recombination event and selection for hped/ebA309 knockout mutants using sucrose was performed as described [Wöhlbrand and Rabus, 2009]. Clones obtained were screened by PCR applying the $e b A 310$ and tioL specific primer pair described above (table 2), and the nucleotide sequence of the knockout region was validated by sequencing.

Complementation plasmids were based on the broad host range plasmid pBBR1MCS-4 [Kovach et al., 1995], containing either hped, ebA309 or both genes (table 2). The forward primer was located 50 bp upstream of the respective start codon to include the ribosomal-binding site. Generated PCR products were cloned into pBBR1MCS-4 using appropriate restriction enzymes (table 2) and plasmids were transferred into the $\Delta$ hped/ebA309 mutant strain after validation as described [Wöhlbrand and Rabus, 2009].
Preparation of total RNA from substrate-adapted cells of strain EbN1 and subsequent amplification of transcripts by RT-PCR was performed as described [Kühner et al., 2005].

\section{Proteomics}

Cultures (400 $\mathrm{ml}$ each) of 4-hydroxyacetophenone-adapted cells of mutant strains as well as wild type 'A. aromaticum' EbN1 were harvested as described [Champion et al., 1999] to obtain cell material for whole-cell shotgun proteome analysis. Cell disruption, reduction, alkylation and tryptic digest were performed as described recently [Zech et al., 2013]. Tryptic peptides were analyzed using a nanoRSLC system (Thermo Fisher Scientific, Germering, Germany) in a trap column mode and equipped with a $25-\mathrm{cm}$ analytical column (C18, $2 \mu \mathrm{m}$ bead size; Thermo Fisher Scientific) coupled online to an ion-trap mass spectrometer (amazon ETD; Bruker Daltonik GmbH, Bremen, Germany). Protein identification was performed using the ProteinScape platform (version 3.1; Bruker Daltonik GmbH) on an in-house Mascot server (version 2.3; Matrix Science Ltd., London, UK) based on the genome sequence of 'A. aromaticum' EbN1 [Rabus et al., 2005] applying a target-decoy strategy as described by Zech et al. [2013].

\section{Cloning of hped Gene and Overexpression in E. coli}

The hped gene was amplified by PCR using the oligonucleotides listed in table 2 . The reaction mixture contained $130 \mathrm{ng}$ of each oligonucleotide; $10 \mathrm{mM}$ dATP, dCTP, dTTP and dGTP, respectively; approximately $30 \mathrm{ng}$ of a plasmid from a genomic library of 'A. aromaticum' EbN1 containing hped, $10 \mu \mathrm{l}$ of 10-times $P f u$ Ultra reaction buffer (Agilent Technologies, Santa Clara, Calif., USA), and 1 U of PfuUltra-DNA-Polymerase (Agilent Technologies) in a total volume of $100 \mu$ l. The mixture was heated for $5 \mathrm{~min}$ at $94^{\circ} \mathrm{C}$ and the gene was amplified by 30 cycles (annealing: $60 \mathrm{~s}$ at $50^{\circ} \mathrm{C}$, polymerization: $120 \mathrm{~s}$ at $72^{\circ} \mathrm{C}$, and melting: $60 \mathrm{~s}$ at $94^{\circ} \mathrm{C}$ ) plus a final extension at $72^{\circ} \mathrm{C}$ for $10 \mathrm{~min}$. PCR products were cleaved with $N d e I$ and $B g l \mathrm{II}$, ligated into a $p \mathrm{JOE} 2702$ vector 
Table 2. Oligonucleotide primers

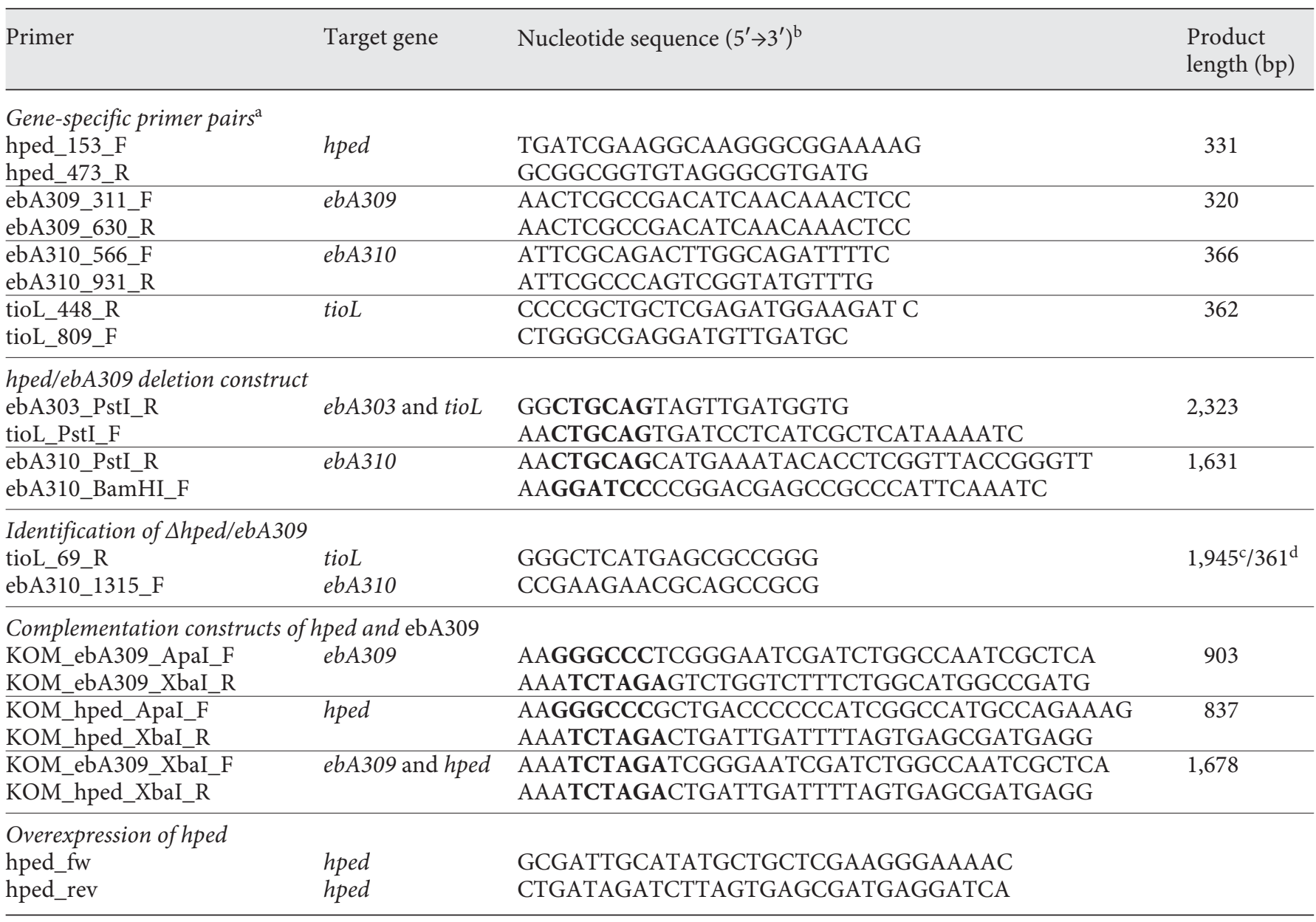

${ }^{\mathrm{a}} \mathrm{R}=$ Reverse primer; $\mathrm{F}=$ forward primer. ${ }^{\mathrm{b}}$ Recognition sites for restriction enzymes are marked in bold type. ${ }^{\mathrm{c}}$ Wild type strain EbN1. ${ }^{\mathrm{d}} \Delta$ hped-ebA309 mutant of strain EbN1.

[Volff et al., 1996] cleaved with NdeI and BamHI (yielding the expression vector $p \mathrm{JOE} \Omega$ hped), and transformed into E. coli strain TG1 [Carter et al., 1985]. Recombinant E. coli cells were grown in LB medium [Sambrook and Russel, 2001] and induced by the addition of $0.2 \%(\mathrm{w} / \mathrm{v})$ rhamnose. After $10 \mathrm{~h}$ of induction, Hped was highly overproduced in soluble form and purified as described below.

Purification of the Overproduced Hped from E. coli

Hped was purified essentially according to the following procedure; for further details see section Purification of Hped in the supplemental material. E. coli cells containing the overproduced Hped were resuspended in protease inhibitor-containing Tris/ $\mathrm{HCl}$ buffer ( $50 \mathrm{mM}, \mathrm{pH} 7.5)$, glass sinter filtered and homogenated with a microfluidizer. The obtained homogenate was stored at $-20^{\circ} \mathrm{C}$. For initial separation by hydrophobic chromatography, the homogenate was amended with ammonium sulfate (20\% saturation) and applied to a phenyl-sepharose FF column (Pharmacia, Uppsala, Sweden). The bulk of enzymatic activity was eluted with a linear gradient to $20 \mathrm{~mm}$ of $\mathrm{Tris} / \mathrm{HCl}$ ( $\mathrm{pH} 7.5$ ) with $10 \%$ isopropanol. Following removal of the isopropanol under a stream of nitrogen gas, further separation by molecular sieve chromatography was achieved with a Superdex prep grade (Pharmacia) operated with $20 \mathrm{mM}$ of sodium phosphate buffer ( $\mathrm{pH}$ 6.8). The activitycontrolled purification of Hped was ultimately achieved by bluesepharose affinity (Pharmacia) and ion exchange chromatography (Mono-Q column, Pharmacia) also run with a phosphate buffer. The ammonium sulfate-precipitated, purified enzyme was dissolved in $10 \mathrm{mM}$ of HEPES/HCl ( $\mathrm{pH}$ 6.8), dialyzed and controlled for homogeneity by SDS-PAGE (see online suppl. fig. 1).

\section{Enzyme Assays}

The oxidation of NADH and concomitant carbonyl reduction was measured by incubating $10 \mu \mathrm{mol}$ of the respective carbonyl compound - added from a 1-M stock solution in DMSO - with 980 $\mu \mathrm{l}$ of potassium phosphate buffer $(50 \mathrm{mM}, \mathrm{pH} 6.5,0.2 \mathrm{mM} \mathrm{NADH}$, $1 \mathrm{mM} \mathrm{MgCl}_{2}$ ). Addition of $10 \mu \mathrm{l}$ of crude extract (approx. $75 \mu \mathrm{g}$ of protein) initiated the reaction which was monitored at $340 \mathrm{~nm}$ 
(Shimadzu, Duisburg, Germany) and $25^{\circ} \mathrm{C} .1$ unit of enzyme activity is defined as the amount of protein reducing $1 \mu \mathrm{mol}$ of ketone per min.

\section{Enantioselectivity}

The stereoselectivity of EbA309 and Hped was determined in the reductive mode in batch reactions with an excess of a secondary alcohol as a hydrogen source. Therewith, the production of chiral compounds from prochiral starting material is monitored rather than the depletion of one of the two enantiomers, which is the case in chiral resolution of a racemic alcohol. This approach (reductive reaction direction) is considered to yield a lower experimental error. $150 \mu$ g of crude protein extract containing EbA309 and Hped, respectively, was mixed with $50 \mu \mathrm{mol}$ of acetophenone and $50 \mu \mathrm{mol}$ of $\mathrm{NAD}^{+}$in potassium phosphate buffer $(50 \mathrm{mM}, \mathrm{pH} 6.5 ; 1 \mathrm{mM}$ $\mathrm{MgCl}_{2}$ ) and $1.3 \mathrm{mmol}$ of propan-2-ol. The resulting product mixture was extracted with one volume of $t \mathrm{BME}$ and analyzed by chiral GC equipped with a Hydrodex b-6TBDM column (25 m; Macherey-Nagel, Düren, Germany). The GC was operated with the following temperature program: start at $90^{\circ} \mathrm{C}$, increase temperature by $3^{\circ} \mathrm{C} \mathrm{min}^{-1}$ to $140^{\circ} \mathrm{C}$ and hold $5 \mathrm{~min}$ at $140^{\circ} \mathrm{C}$.

\section{Protein Crystallization and Data Collection}

Crystals of purified Hped were grown with the sitting drop method in a buffer containing 30\% PEG 6000, $0.1 \mathrm{M} \mathrm{Na}$-cacodylate ( $\mathrm{pH}$ 6.5) and $0.3 \mathrm{M} \mathrm{Mg-acetate.} \mathrm{Prior} \mathrm{to} \mathrm{data} \mathrm{collection,} \mathrm{one} \mathrm{crystal}$ was soaked in $1 \mathrm{mM} \mathrm{NAD}^{+}$for $4 \mathrm{~h}$. The data for the apo- and for the $\mathrm{NAD}^{+}$-soaked form were collected at the PX III beam line at the synchrotron Swiss Light Source (Villigen, Switzerland). The crystals were flash frozen in a cold nitrogen stream at $100 \mathrm{~K}$. The crystals belong to the monoclinic space group $\mathrm{C} 2$ with cell parameters of $a=121.5 \AA, b=55.1 \AA, c=86.3 \AA$ and $\beta=134.4^{\circ}$. An overview of the $\mathrm{X}$-ray data collection is provided in online supplementary table 1 .

\section{Structure Determination and Refinement}

The structure of the holo-form of Hped was solved by molecular replacement with the program MOLREP as part of the CCP4 package [Winn et al., 2011]. The phasing model was levodione reductase (PDB accession code 1IY8) [Sogabe et al., 2003], which has $38 \%$ amino acid sequence identity with Hped. Monomer A was pruned with the program CHAINSAW from the CCP4 package. The Matthews coefficient anticipated two monomers per asymmetric unit. MOLREP produced a solution with a dimer for the $\mathrm{NAD}^{+}$data set. Subsequent cycles of refinement with the program refmac5 from the CCP4 suite and model building with COOT [Emsley et al., 2010] further decreased the R-factor. Water molecules, $5 \mathrm{Mg}^{2+}$ ions, 5 acetate molecules and one partially occupied sulfobetaine molecule (occupancy 0.5 for the propane sulfonate chain) were added as suggested by the electron density and the protein environment. The refinement procedure resulted in a final model with an R-factor of $0.11\left(R_{\text {free }}=0.14\right)$ and good stereochemistry. The final protein model of the holo-enzyme was used as the starting model for the apo-structure. Several cycles of refinement und manual rebuilding resulted in an R-factor of $0.17\left(R_{\text {free }}=0.22\right)$. An overview of the structure refinement statistics is given in table S1 in the supplementary material. Ramachandran plots were generated using the program COOT [Emsley et al., 2010].

Docking

The substrates 4-hydroxyacetophenone and acetophenone were docked with the docking software GLIDE (Schrödinger Inc., Portland, Oreg., USA) [Halgren et al., 2004] into the active sites of Hped and Ped. The molecules were created with the 2D sketcher and converted to a $3 \mathrm{D}$ structure, and the geometrics were optimized. The polar hydrogens of the active site residues $\operatorname{Tyr}^{155}$ and Ser ${ }^{142}$ were placed manually in reasonable positions. Default parameters were used for the preparation of the ligands with LigPrep, the grid generation and GLIDE SP docking.

\section{Database Submission}

Coordinates of the apo- and holo-structures have been deposited in the Protein Data Bank (entries 4ure and 4urf).

\section{Acknowledgements}

We thank R. Reinhardt (Köln) for providing cloned hped, Petra Reis (Ludwigshafen) for crystallization and Wolfgang Houy (Ludwigshafen) for data collection. This work was supported by the FOL program of the Carl von Ossietzky University Oldenburg.

\section{References}

Abokitse K, Hummel W: Cloning, sequence anal- Carter P, Bedouelle H, Winter G: Improved oligoysis, and heterologous expression of the gene encoding a (S)-specific alcohol dehydrogenase from Rhodococcus erythropolis DSM 43297. Appl Microbiol Biotechnol 2003;62: 380-386.

Breuer M, Rabus R, Heider J: Method for producing optically active alcohols using Azoarcus sp. EbN1 dehydrogenase. US Patent No WO2008/155302 A1. 2008

Carmona M, Zamarro MT, Blázquez B, DuranteRodríguez G, Juárez JF, Valderrama JA, Barragán MJL, García JL, Díaz E: Anaerobic catabolism of aromatic compounds: a genetic and genomic view. Microbiol Mol Biol Rev 2009;73:71-133. nucleotide site-directed mutagenesis using M13 vectors. Nucl Acids Res 1985;13:44314443.

Champion KM, Zengler K, Rabus R: Anaerobic degradation of ethylbenzene and toluene in denitrifying strain $\mathrm{EbN} 1$ proceeds via independent substrate-induced pathways. J Mol Microbiol Biotechnol 1999;1:157-164.

Dudzik A, Snoch W, Borowiecki P, OpalinskaPiskorz J, Witko M, Heider J, Szaleniec M: Asymmetric reduction of ketones and $\beta$-keto esters by (S)-1-phenylethanol dehydrogenase from denitrifying bacterium Aromatoleum aromaticum. Appl Microbiol Biotechnol 2015;99:5055-5569.
Emsley P, Lohkamp B, Scott WG, Cowtan K: Features and development of Coot. Acta Crystallogr D Biol Crystallogr 2010;66:486-501.

Fuchs G, Boll M, Heider J: Microbial degradation of aromatic compounds - from one strategy to four. Nat Rev Microbiol 2011;9:803-816.

Ghosh D, Weeks CM, Grochulski P, Duax WL, Erman M, Rimsay RL, Orr JC: Three-dimensionalstructureofholo $3 \alpha, 20 \beta$-hydroxysteroid dehydrogenase: a member of a short-chain dehydrogenase family. Proc Natl Acad Sci USA 1991;88:10064-10068.

Gibson J, Harwood CS: Metabolic diversity in aromatic compound utilization by anaerobic microbes. Annu Rev Microbiol 2002;56:345369 . 
- Gröger H, Chamouleau F, Orologas N, Rollmann C, Drauz K, Hummel W, Weckbecker A, May O: Enantioselective reduction of ketones with 'designer cells' at high substrate concentrations: highly efficient access to functionalized optically active alcohols. Angew Chem Int Ed 2006; 45:5677-5681.

-Halgren TA, Murphy RB, Friesner RA, Beard HS, Frye LL, Pollard WT, Banks JL: Glide: a new approach for rapid, accurate docking and scoring. 2. Enrichment factors in database screening. J Med Chem 2004;47:1750-1759.

- Höffken HW, Duong M, Friedrich T, Breuer M, Hauer B, Reinhardt R, Rabus R, Heider J: Crystal structure and enzyme kinetics of the (S)-specific 1-phenylethanol dehydrogenase of the denitrifying bacterium strain EbN1. Biochemistry 2006;45:82-93.

-Hummel W: Large-scale applications of NAD(P) dependent oxidoreductases: recent developments. Trends Biotechnol 1999;17:487-492.

- Javidpour P, Pereira JH, Goh EB, McAndrew RP, Ma SM, Friedland GD, Keasling JD, Chhabra SR, Adams PD, Beller HR: Biochemical and structural studies of NADH-dependent FabG used to increase the bacterial production of fatty acids under anaerobic conditions. Appl Environ Microbiol 2014;80:497-505.

-Jobst B, Schühle K, Linne U, Heider J: ATP-dependent carboxylation of acetophenone by a novel type of carboxylase. J Bacteriol 2010; 192:1387-1394.

-Jörnvall H, Hedlund J, Bergman T, Oppermann U, Persson B: Superfamilies SDR and MDR: from early ancestry to present forms. Emergence of three lines, a Zn-metalloenzyme, and distinct variabilities. Biochem Biophys Res Comm 2010;396:125-130.

Jörnvall H, Persson M, Jeffery J: Alcohol and polyol dehydrogenases are both divided into two protein types, and structural properties crossrelate the different enzyme activities within each type. Proc Natl Acad Sci USA 1981;78: 4226-4230.

Kallberg Y, Oppermann U, Jörnvall H, Persson B: Short-chain dehydrogenases/reductases (SDRs). Coenzyme-based functional assignments in completed genomes. Eur J Biochem 2002;269:4409-4417.

-Kaser FM, Coates JD: Nitrate, perchlorate and metal respires; in Timmis KN (ed): Handbook of Hydrocarbon and Lipid Microbiology. Springer, Berlin, 2010, pp 2033-2047.

-Kloer DP, Hagel C, Heider J, Schulz GE: Crystal structure of ethylbenzene dehydrogenase from Aromatoleum aromaticum. Structure 2006;14:1377-1388.

Kniemeyer O, Heider J: Ethylbenzene dehydrogenase, a novel hydrocarbon-oxidizing molybdenum/iron-sulfur/heme enzyme. J Biol Chem 2001a;276:21381-21386.

Kniemeyer O, Heider J: (S)-1-phenylethanol dehydrogenase of Azoarcus sp. strain EbN1, an enzyme of anaerobic ethylbenzene catabolism. Arch Microbiol 2001b;176:129-135.
Kovach ME, Elzer PH, Hill DS, Robertson GT, Farris MA, Roop II RM, Peterson KM: Four new derivatives of the broad-host-range cloning vector $\mathrm{pBBR} 1 \mathrm{MCS}$ carrying different antibiotic-resistance cassettes. Gene 1995;166: 175-176.

-Kühner S, Wöhlbrand L, Fritz I, Wruck W, Hultschig C, Hufnagel P, Kube M, Reinhardt $\mathrm{R}$, Rabus R: Substrate-dependent regulation of anaerobic degradation pathways for toluene and ethylbenzene in a denitrifying bacterium, strain EbN1. J Bacteriol 2005; 187:14931503.

Ladenstein R, Winberg J-O, Benach J: Structurefunction relationships in short-chain alcohol dehydrogenases. Cell Mol Life Sci 2008;65: 3918-3935.

MacKintosh RW, Fewson A: Microbial aromatic alcohol and aldehyde dehydrogenases: in Weiner H, Flynn TG (eds): Enzymology and Molecular Biology of Carbonyl Metabolism. New York, Alan R. Liss, 1987.

-Niefind K, Müller J, Riebel B, Hummel W, Schomburg D: The crystal structure of $R$-specific alcohol dehydrogenase from Lactobacillus brevis suggests the structural basis of its metal dependency. J Mol Biol 2003;327:317-328.

-Oppermann U, Filling C, Hult M, Shafqat N, Wu X, Lindh M, Shafqat J, Nordling E, Kallberg Y, Persson B, Jörnvall H: Short-chain dehydrogenases/reductases (SDR): the 2002 update. Chem Biol Interact 2003;143-144:247-253.

-Pérez-Pantoja D, Donoso R, Agulló L, Córdova M, Seeger M, Pieper DH, González B: Genomic analysis of the potential for aromatic compounds biodegradation in Burkholderiales. Environ Microbiol 2012;14:1091-1117.

Prelog V: Specification of the stereospecificity of some oxido-reductases by diamond lattice sections. Pure Appl Chem 1964;9:119-130.

Rabus R, Kube M, Beck A, Widdel F, Reinhardt R: Genes involved in the anaerobic degradation of ethylbenzene in a denitrifying bacterium, strain EbN1. Arch Microbiol 2002;178:506516.

Rabus R, Kube M, Heider J, Beck A, Heitmann K, Widdel F, Reinhardt R: The genome sequence of an anaerobic aromatic-degrading denitrifying bacterium, strain EbN1. Arch Microbiol 2005; 183:27-36.

Rabus R, Trautwein K, Wöhlbrand L: Towards habitat-oriented systems biology of 'Aromatoleum aromaticum' EbN1. Chemical sensing, catabolic network modulation and growth control in anaerobic aromatic compound degradation. Appl Microbiol Biotechnol 2014;98:3371-3388.

Rabus R, Widdel F: Anaerobic degradation of ethylbenzene and other aromatic hydrocarbons by new denitrifying bacteria. Arch Microbiol 1995; 163:96-103.

Reeve CD, Carver MA, Hopper DJ: Stereochemical aspects of the oxidation of 4-ethylphenol by the bacterial enzyme 4-ethylphenol methylenehydroxylase. Biochem J 1990;269:815819.
Sambrook J, Russel DW: Molecular Cloning: A Laboratory Manual, ed 3. Cold Spring Harbor, Cold Spring Harbor Laboratory Press, New York, 2001.

Schäfer A, Tauch A, Jäger W, Kalinowski J, Thierbach G, Pühler A: Small mobilizable multi-purpose cloning vectors derived from the Escherichia coli plasmids pK18 and pK19: selection of defined deletions in the chromosome of Corynebacterium glutamicum. Gene 1994;145:69-73.

- Sogabe S, Yoshizumi A, Fukami TA, Shiratori Y, Shimizu S, Takagi H, Nakamori S, Wada M: The crystal structure and stereospecificity of levodione reductase from Corynebacterium aquaticum M-13. J Biol Chem 2003;278: 19387-19395.

Widdel F, Knittel K, Galushko A: Anaerobic hydrocarbon-degrading microorganisms: an overview; in Timmis KN (ed): Handbook of Hydrocarbon and Lipid Microbiology. Berlin, Springer, 2010, pp 1997-2021.

-Widdel F, Musat F: Diversity and common principles in enzymatic activation of hydrocarbons; in Timmis KN (ed): Handbook of Hydrocarbon and Lipid Microbiology. Berlin, Springer, 2010, pp 983-1009.

Widdel F, Rabus R: Anaerobic biodegradation of saturated and aromatic hydrocarbons. Curr Opin Biotechnol 2001;12:259-276.

-Wöhlbrand L, Kallerhoff B, Lange D, Hufnagel P, Thiermann J, Reinhardt R, Rabus R: Functional proteomic view of metabolic regulation in 'Aromatoleum aromaticum' strain EbN1. Proteomics 2007;7:2222-2239.

Wöhlbrand L, Rabus R: Development of a genetic system for the denitrifying bacterium 'Aromatoleum aromaticum' strain EbN1. J Mol Microbiol Biotechnol 2009;17:41-52.

-Wöhlbrand L, Wilkes H, Halder T, Rabus R: Anaerobic degradation of $p$-ethylphenol by 'Aromatoleum aromaticum' strain EbN1: pathway, regulation and involved proteins. J Bacteriol 2008;190:5699-5709.

-Volff J-N, Eichenseer C, Viell P, Piendl W, Altenbuchner J: Nucleotide sequence and role in DNA amplification of the direct repeats composing the amplifiable element AUD1 of Streptomyces lividans 66. Mol Microbiol 1996; 21:1037-1047.

-Winn MD, Ballard CC, Cowtan KD, Dodson EJ, Emsley P, Evans PR, Keegan RM, Krissinel EB, Leslie AGW, McCoy A, McNicholas SJ, Murshudov GN, Pannu NS, Potterton EA, Powell HR, Read RJ, Vagin A, Wilson KS: Overview of the CCP4 suite and current developments. Acta Crystallogr D Biol Crystallogr 2011;67:235-242.

Zech H, Hensler M, Koßmehl S, Drüppel K, Wöhlbrand L, Trautwein K, Hulsch R, Maschmann U, Colby T, Schmidt J, Reinhardt R, Schmidt-Hohagen K, Schomburg D, Rabus R: Adaptation of Phaeobacter inhibens DSM 17395 to growth with complex nutrients. Proteomics 2013;13:2851-2868. 